\title{
Performance of a damage-protected highway bridge pier subjected to bi-directional earthquake attack
}

\author{
K. Solberg ${ }^{1}$, N. Mashiko ${ }^{2}$, J.B. Mander $^{3}$ \& R.P. Dhakal ${ }^{4}$
}

\begin{abstract}
Recent earthquakes such as Loma Prieta, Northridge, and Kobe have demonstrated a need for a new design philosophy of bridge piers that avoids damage in order to ensure post-earthquake serviceability and reduce financial loss. Damage Avoidance Design (DAD) is one such emerging philosophy that meets these objectives. DAD details require armoring of the joints; this eliminates the formation of plastic hinges. Seismic input energy is dissipated by rocking coupled with supplemental energy dissipation devices. In this paper the theoretical performance of a DAD bridge pier is validated through bi-directional quasi-static and pseudodynamic tests performed on a $30 \%$ scale specimen. The DAD pier is designed to rock on steel-steel armored interfaces. Tension-only energy dissipaters are used to increase tie down forces and further reduce dynamic response. The seismic performance of the DAD pier is compared to that of a conventional ductile pier. Results show that one can have 90 percent confidence that the DAD pier will survive a design basis earthquake without sustaining any damage, whereas for the conventional design substantial damage is sustained.
\end{abstract}

CE database subject headings:

Bridge abutments, Damage prevention, Pseudodynamic method, Precast concrete. Post-tensioning

\section{INTRODUCTION}

Current seismic engineering standards for reinforced concrete bridge piers tolerate a degree of inelastic behavior when subjected to design level ground motions, resulting in the formation of plastic hinges to provide ductile behavior. As a direct consequence, damage to the pier is unavoidable and may also result in significant residual displacement and potential closure of the bridge as the pier is repaired or replaced. Although the ductile design methodology does afford economic (inelastic) structures with good life-safety (ductile) characteristics, damage is inherent and the financial losses due to repair or replacement coupled with down-time from closure of transportation arteries can be devastating. As the end-user community is demanding more in terms of post-earthquake serviceability, a Damage Avoidance Design (DAD) philosophy is emerging which attempts to ensure that post-earthquake serviceability demands are met.

The concept of rocking structures is an effective solution to this problem. Original investigations by Housner (1963) examined the free vibration behavior of rigid blocks. Subsequent studies considered flexibility (Meek 1978) coupled with rocking systems and prestress (Aslam et al. 1980) as a means of anchoring a structure to the ground and thus increasing its lateral capacity. More recently, these concepts have been carried over to bridge piers as presented by Mander and Cheng (1997) and Mander (2000 and 2004); the philosophy was similarly brought to precast concrete buildings using beam-column joints and structural walls by Priestley et al. (1999). Though still not common, two state-of-the-practice examples of rocking structures can be found in New

\footnotetext{
${ }^{1}$ Graduate Research Assistant, University of Canterbury, Private Bag 4800, Christchurch, New Zealand

${ }^{2}$ Former Graduate Student, University of Canterbury, Private Bag 4800, Christchurch, New Zealand

${ }^{3}$ Professor, Texas A\&M University, College Station, Texas, USA

${ }^{4}$ Senior Lecturer, University of Canterbury, Private Bag 4800, Christchurch, New Zealand
} 
Zealand: the South Rangitikei Railway Bridge and an industrial chimney at Christchurch International Airport (Skinner et al. 1993).

Analytical and experimental investigations of such systems performed by Mander and Cheng (1997) adopt a displacement-based approach to design bridges for damage avoidance. They derived relationships through standard rigid-body kinematics. The method was confirmed by unidirectional cyclic loading and shake-table tests performed on reinforced concrete bridge piers, with and without unbonded post-tensioned prestress, and steel interface plates between the pier and foundation. No damage to the specimen was observed in these tests. However, bi-directional tests were not performed which would better represent actual ground motions. Palermo et al. (2005) investigated the performance of the "hybrid" controlled rocking system applied to bridge piers and the global response of this system with regular and irregular pier configurations. Results indicate improved performance of rocking systems when compared to conventional ductile detailing.

This study will further investigate the seismic response of rocking bridge piers. As an extension to the uni-directional tests described by Mander and Cheng (1997) and Mander (2000 and 2004), a scaled bridge pier with an armored interface is subjected to bi-directional quasi-static (QS) and pseudodynamic (PD) loading patterns. Special attention is given to the large concentrated forces which need to be transmitted through a small region of the specimen due to bi-directional rocking behavior.

\section{EXPERIMENTAL PROGRAM}

The prototype DAD bridge pier was detailed using the principles of a damage avoidance philosophy and scaled to fit available experimental facilities. QS and PD tests were performed, simulating the performance of the pier subjected to real earthquake ground motions. Earthquake records were chosen from a suite of twenty ground motions based on an Incremental Dynamic Analysis (IDA) (Vamvatsikos and Cornell 2004). Following the procedure established by Dhakal et al. (2006), records were chosen to represent the $90^{\text {th }}$ percentile design basis earthquake (DBE), with a $10 \%$ chance of occurrence in 50 years, $50^{\text {th }}$ percentile maximum considered earthquake (MCE), with a $2 \%$ chance of occurrence in 50 years, and the $90^{\text {th }}$ percentile MCE. Damage to the pier was monitored and classified according to the Hazus damage states index described for bridges by Mander and Basoz (1999).

\section{Prototype Design}

The prototype bridge pier is $7 \mathrm{~m}$ high and taken from a typical 'long' multi-span highway bridge on firm soil with $40 \mathrm{~m}$ longitudinal spans and a $10 \mathrm{~m}$ transverse width. Design details are presented in Table 1 and Figure 1(a). The seismic weight of the superstructure was calculated to be $7000 \mathrm{kN}$. The pier was assumed to be located in a high seismic zone in New Zealand, with the DBE having a peak ground acceleration (PGA) of $0.4 \mathrm{~g}$. The moment demand was assessed according to the New Zealand seismic design standard (NZS:3101 1995) considering a ductile monolithic pier; this was calculated to be $7436 \mathrm{kN}-\mathrm{m}$.

The moment capacity, $M$, of the DAD pier is satisfied by a combination of gravity load, longitudinal un-bonded tendons, and supplemental energy dissipation devices. Assuming the pier will behave in an essentially rigid fashion, rigid body kinematics can be employed to predict the pier's response to seismic excitation. The moment necessary for uplift, $M_{\text {uplift }}$, can be calculated from:

$$
M_{\text {uplift }}=(P+F) B / 2+A_{s} \sigma_{y}(2 e+B) / 2
$$

where $P=$ axial load; $F=$ effective prestress force; $B=$ width of the rocking base; $A_{s}=$ cross sectional area of the energy dissipaters; $\sigma_{\mathrm{y}}=$ yield stress of the energy dissipaters; and $e=$ eccentricity of the energy dissipaters from the pier centerline. 
Although rocking in a horizontal interface is likely to provoke vertical acceleration, this and any other vertical excitations are neglected in this study. Assuming $P$ is in effect fixed, the required moment capacity can be reached by modifying either the geometry of the rocking interface, adding additional pre-stress, or adding dissipaters. The post-uplift (rocking) behavior of the pier is a function of the initial prestress and the elastic properties of the tendons. To determine the displacement of the pier at uplift, it is necessary to consider the elastic behavior of the pier prior to this point. This is a function primarily of the moment of inertia, $I$. Customary practice considers an effective moment of inertia, $I_{\text {eff, }}$ as a function of $I_{g}$ (the gross uncracked moment of inertia), which is essentially constant over the height of the pier. Once rocking commences, however, reaction to the vertical load is an eccentric point force about one edge (or corner in the case of biaxial loading) of the pier. Thus, at the base of the pier, there is a portion of the column that does not participate in the bending resistance. Following St. Venant's principle, a 45 degree cut from the rocking interface can be made and a modified effective stiffness can be calculated. For the pier concerned this has been calculated as $I_{\text {eff }}=0.25 I_{g}$.

The theoretical pushover curve of the DAD pier is presented in Figure 1(c), which is generated from rigid-body kinematics (Mander and Cheng 1997). The first straight line shows elastic deformation of the pier. The second line represents the rocking phase. The dissipaters (if present) would yield at the beginning of this phase. The stiffness in this phase comes mainly from the prestressing tendons. This phase ends with the yielding of these tendons, which is calculated to occur at a drift of about 3\% (not shown in the figure) in this case. After this yielding drift, the displacement/drift continues to increase at a constant force until the tendons break at a very high drift; i.e. in the order of $10 \%$. Since the post-yield response of the DAD pier is limited to the rocking region, it is implied that the pier itself will not form a plastic hinge, and can therefore be detailed according to nominal longitudinal and transverse reinforcement requirements.

\section{Specimen Construction}

A scaled model of the prototype bridge pier was constructed. Figures 1(b), (d), (e) and (f) present an elevation of the specimen, a detail of the dissipaters, a photo of the shoe block, and details of the shoe block reinforcement, respectively. Longitudinal and transverse reinforcement ratios were kept the same in the physical model and the prototype pier.

The specimen was constructed in four parts: (i) the base block; (ii) circular column; (iii) head block; and (iv) shoe block. As the base block and head block were considered part of the experimental testing apparatus, they were detailed to withstand the expected demands from testing. At the top of the base block, Plate $\mathrm{C}$, with a $350 \times 350 \mathrm{~mm}$ hole in the centre, was placed flush to the top of the base block to act as the armored rocking interface of the pier's foundation. To construct the interface at the base of the column, Plate B was bolted to Plate A to form the shear key which would rest in the square hole of Plate C. A $3 \mathrm{~mm}$ gap was provided on each side to prevent the steel plates from grinding during rocking. Longitudinal reinforcement was tack welded into holes drilled in Plate A. The R6 spirals were wrapped around these longitudinal bars. The pier was poured without completing the shoe block. To finish the shoe block, a portion of the cover concrete of the pier was jack hammered off to expose the longitudinal reinforcement. Three D16 grade $500 \mathrm{MPa}$ bars were tack welded to Plate A at each corner and to the pier's longitudinal reinforcement, creating a diagonal mechanism to resist expected strut forces. Additional D16 'hoop' bars were placed parallel to each plate edge. Two layers of high strength wire rope $(7 \times 19$ construction) were wrapped around the inner diagonal reinforcement and the outer cage. This was intended to provide improved confinement to the concrete and thus prevent excessive cracking. The shoe block was poured separately from the circular pier using a high strength concrete mix with $1 \%$ steel fibers (DRAMIX $^{\mathrm{TM}}$ ) by weight.

The energy dissipaters consisted of R12 threaded bars with the centre $150 \mathrm{~mm}$ machined to a $7 \mathrm{~mm}$ diameter (Figure 1(d)). These devices were screwed vertically into Plate $\mathrm{C}$ through ducts at 
each corner of the shoe block, bolted in place, and stressed to $0.5 f_{y}$ by torque wrench. Since damage from earthquakes can largely be attributed to large initial pulses, particularly during near field events, the dissipaters were designed to perform in tension only, with the intent they could be easily replaced following a seismic event.

\section{The Test Apparatus}

An elevation and plan view of the testing apparatus is given in Figure 2(a) and (b), respectively. The apparatus was designed to simulate actual seismic demands imposed on the prototype structure. To accomplish this, simultaneous lateral loads combined with axial load were applied to the specimen via two actuators mounted on reaction frames. These frames were assembled within the confines of a $10,000 \mathrm{kN}$ capacity DARTEC ${ }^{\mathrm{TM}}$ universal testing machine. At the top and bottom of the specimen, a ball joint transmitted a constant axial load of $777 \mathrm{kN}$, consisting of the weight of the superstructure $(630 \mathrm{kN})$ and the simulated force from un-bonded tendons $(147 \mathrm{kN})$. The L-shaped reaction frames were attached to counter weight baskets by $30 \mathrm{~mm}$ diameter high strength rods running through the base block. Lateral loads were applied via $800 \mathrm{kN}$ capacity hydraulic actuators, each actuator being connected to the specimen's head block and reaction frame by universal joints. A photograph of the test setup is given in Figure 2(c).

Instruments used in the test are illustrated in Figure 2(d). A primary rotary potentiometer was installed in line with each actuator to measure the displacement of the specimen to be used by the controller's PD algorithm. Two additional rotary pots were installed at the top and bottom of the shoe block along with a series of spring pots at each corner to measure localized uplift. All instrumentation was isolated on the testing apparatus to measure relative displacement. Load cells (1000kN capacity) were installed in-series with the actuators.

\section{Pseudodynamic Testing Theory}

The PD testing concept is illustrated in Figure 2(d). Two linked systems are required to perform testing: an analytical system and a physical system representing the analytical model. The process originates from the well-known equation of motion:

$$
m \ddot{u}+c \dot{u}+k u=-m \ddot{u}_{g}(t)
$$

where $m=$ mass; $c=$ damping; $k=$ stiffness; $\ddot{u}_{g}=$ ground acceleration; $u=$ displacement; $\dot{u}=$ first derivative of $u$ (velocity); $\ddot{u}=$ second derivative of $u$ (acceleration); and $t=$ time.

Given an assumed $m$ and $c$, it is possible to determine $k$ through physical experimentation, and $u$ can be solved. This was performed in a closed loop, whereby $\ddot{u}_{g}$ was input from an earthquake record consisting of a series of ground accelerations at a given time step. From a userdefined initial stiffness, the analytical system calculated $u$, then instructed the test apparatus to move the specimen to the calculated displacement, at which time the physical stiffness was recorded from the specimen. Calling this step $n$, the analytical system then applied $\ddot{u}_{g}$ at the next $n+1$ time step using $k_{n}$ to solve for $u_{(n+1)}$, thus completing the loop. This process was repeated until the acceleration data set terminated. A detailed explanation of the PD testing concept is given in Shing et al. (1996).

In the case of this study, calculations performed in the analytical system were consistent with the prototype (full scale) system. Displacements and forces were scaled when sent to or retrieved from the physical model; displacements were scaled by $\lambda=0.3$ and forces by $1 / \lambda^{2}=11.11$.

\section{Input Data}

The bi-directional QS test implemented in testing consisted of a "clover leaf" shape loading path, illustrated in Figure 3(e), (f) and (g). This displacement profile was selected to validate the calculated stiffness and moment capacity of the specimen. 
For PD testing, the aforementioned mass, $m$, and effective viscous damping, $\xi_{\text {eff, }}$ are required to solve the equation of motion. The latter can be assessed by:

$$
\xi_{\text {eff }}=\xi_{0}+\xi_{\text {rocking }}
$$

in which $\xi_{0}=$ intrinsic damping; $\xi_{\text {rocking }}=$ effective viscous damping from the radiation of energy by rocking impacts. According to Mander and Cheng (1997), the following equation can be used:

$$
\xi_{\text {rocking }}=2 / \pi \times D_{c} / H_{c}
$$

where $D_{c}=$ the width of the shoe block and $H_{c}=$ the height of the pier. For the present specimen $\xi_{\text {rocking }}=3.75 \%$. Herein it will be assumed $\xi_{0}=2 \%$ which is customarily adopted for prestressed concrete structures, thus $\xi_{\text {eff }}=5.75 \%$.

\section{Earthquake Records}

To determine the earthquake records used for PD testing a procedure described by Dhakal et al. (2006) was adopted. In their study, PD tests were performed on a bridge pier where the earthquake records adopted for testing were selected based on IDA. A suite of twenty earthquakes were adopted as potential candidates based on a previous study conducted by Vamvatsikos and Cornell (2004). These records range in magnitude between 6.5 and 6.9, have moderate epi-central distance, and were recorded on firm soil. The IDA data from these records was analyzed probabilistically to identify those critical to the piers. Three records were chosen to represent the $90^{\text {th }}$ percentile DBE $(10 \% / 50$ years $)$ and the $50^{\text {th }}$ and $90^{\text {th }}$ percentile MCE (2\%/50 years). Since this study will highlight the enhanced performance of a DAD bridge pier, it is necessary to directly compare its performance to that of a conventional ductile pier. To accomplish this, specific earthquake selection for the DAD pier was not performed; the same earthquakes selected for the New Zealand ductile bridge pier have been adopted for this study. These earthquakes, termed EQ1 (90\% DBE), EQ2 (50\% MCE), and EQ3 (90\% MCE), are given in Table 2. In the test, these three records were applied consecutively, with 5 second intervals of zero acceleration between each record. The interval allowed the residual drift and natural period of the structure to be recorded.

\section{Damage Limit States}

All observed damage to the shoe block was classified according to the Hazus damage limit states index presented in Table 3 (Mander and Basoz 1999). These damage states (DS) were developed for ductile monolithic bridge piers, and are modified (i.e. redefined) here to apply to the DAD system. DS1 represents pre-yield response and therefore no damage to the structure; hence a representative limit is the uplift drift of the structure. When considering a structure designed for damage avoidance, ideally the structure would not pass this limit until the full collapse, i.e. DS5. The intermediate damage states, DS2, DS3, and DS4, are somewhat subjective and defined for various magnitudes of damage. The boundary for DS2 and DS3 is defined as being the point at which the structure would be unusable until repairs are made. Similarly, the boundary for DS3 and DS4 would be the point at which the structure is deemed irreparable; components must be rebuilt or the entire structure must be replaced. Finally, DS5 represents full collapse of the structure. In the case of a DAD structure, it should not experience DS3 or DS4 because of the rocking mechanism. DS2 may result when yielding of the post-tensioned tendons occurs, or aesthetic cracks and minor spalling is noticeable. Such repairs would be minor and the pier should remain fully operational. 


\section{EXPERIMENTAL RESULTS}

\section{Quasi-Static Test (QS Test)}

The performance of the DAD pier under the bi-directional clover leaf QS test is presented in Figure 3. Note the data from each figure is projected to the next. The eight distinct loops found in Figures 3(a) and (e) show the force and displacement profile of the pier, respectively. The pier seems to behave in a similar fashion in all quadrants. Figures 3(b) and (d) show that the pier remained elastic with slight hysteretic damping in the east-west (EW) and north-south (NS) components up to $2 \%$ drift. Figure 3 (c) shows the specimen in the testing machine. Of particular note is the negligible residual drift observed.

\section{Pseudodynamic Test (PD Test)}

The specimen was subject to two PD tests: the first without energy dissipaters and the second with energy dissipaters. Figure 4 presents results from the experiment that used energy dissipaters. Similar to the QS test, the results are plotted so that data from one graph is projected to the next, resulting in two force-displacement curves (Figures 4(b) and (d)), two displacement history curves (Figures 4(f) and (h)) and a plan view of bi-directional displacement (Figure 4(d)). In addition, the theoretical prediction given in Figure 1(c) is plotted along with the forcedisplacement curve of Figure 4(b). Good agreement between the prediction and the experimental result is evident. Maximum drifts observed during EQ1 in the EW and NS direction were 1.91\% and $-1.80 \%$ at 6.48 seconds and 14.94 seconds, respectively. The corresponding lateral forces were $90.6 \mathrm{kN}$ and $-80.4 \mathrm{kN}$. No damage to the pier was observed from EQ1, aside from some minor hairline cracks diagonally from the bottom corners to top midsection of the shoe block. Additionally, tensile bending cracks were observed along the circular pier; these closed and were undetectable after testing. After EQ1, the pier was classified at DS1: no damage.

The maximum drift observed during EQ2 in the EW and NS direction was $3.83 \%$ and $2.15 \%$ at 36.42 seconds and 38.34 seconds, respectively. The corresponding lateral loads were $96.5 \mathrm{kN}$ and $90.9 \mathrm{kN}$. A photograph of the shoe block at approximately $3 \%$ drift (at 37 seconds) is given in Figure $4(\mathrm{~g})$. At times the pier was rocking on a single corner of the shoe block, such as when the drift of the pier was at $2 \%$ in both the NS and EW direction at approximately 39 seconds. This resulted in minor crushing and additional hairline cracks at the diagonal, as shown in Figure 4(i). Such damage was largely aesthetic and did not cause noticeable degradation of strength or stiffness, thus the pier was classified as being at DS2: slight damage.

The pier did not survive EQ3. At 13.5 seconds the displacement of the pier was $5.5 \%$ in the EW direction and $1.2 \%$ in the NS. It was deemed unsafe to continue testing, thus resulting in an assumed complete collapse of the structure under EQ3. Aside from this, there appeared to be only minor additional damage; further crushing and hairline cracks were observed, but were considered to be insufficient to justify damage beyond DS2. However, since complete collapse was assumed due to termination of the test, the pier was classified at DS5.

Figure 4(c) presents a comparison of the hysteretic response of the pier with and without energy dissipaters. Results are presented for EQ1 and EQ2. The energy dissipation devices had a small contribution to the overall behavior of the specimen. The maximum lateral force in the EW and NS direction for EQ1 increased 3\% and 4\%, respectively. For EQ2 there was a similar increase in strength, 7\% and $4 \%$ for the EW and NS, respectively.

Strain gauges attached to the longitudinal steel $50 \mathrm{~mm}$ from the base did not detect yielding, which would have occurred at approximately $1 \%$ drift had it been a conventional monolithic pier. Supplemental instrumentation recorded that rocking of the shoe block was generally about $1 \%$ drift less than rocking of the entire specimen, indicating that following uplift through to collapse, the total pier deformation included $1 \%$ drift of elastic flexural deformation. During the zero acceleration portion of testing no discernable residual displacements were observed. 


\section{COMPARISON WITH A CONVENTIONAL DUCTILE PIER}

To highlight the advantages of DAD, the specimen's performance was compared to that of a companion conventional monolithic pier (Dhakal et al. 2006) designed to the seismic design code of New Zealand (NZS3101 1995). The prototype details are given in Table 1. The pier was subject to the same PD testing as the DAD pier. Figure 5 presents experimental results of the ductile pier for EQ1, EQ2 and EQ3. Figure 5(a) presents a photograph taken after spalling occurred, (c) is a photo after bar buckling occurred, (b) and (d) give force-displacement for the EW and NS, respectively, (e) gives a plan view of the drift orbit, and (f) and (g) give displacement versus time plots. It is apparent from this figure that the ductile pier has a higher stiffness and a higher moment capacity than the DAD pier. This is due to the different design procedures of the two piers. Consequently, maximum displacement for the two piers varied considerably. However, in spite of greater displacements, the DAD pier suffered considerably less damage and no residual displacement. After EQ1 and EQ2, the ductile pier was classified as being in DS2. As is evident from Figure 4 and Figure 5, the residual drift for the DAD pier was essentially zero, while for the ductile pier this was approximately $0.25 \%$. After EQ3, testing was terminated due to high drift, resulting in DS5. Although the final collapse condition was similar during EQ3, considerably less damage was observed in the DAD pier after EQ1 and EQ2.

Note that the primary objective of DAD is not to reduce the structural response, is rather to minimize (if not possible to completely avoid) damage. Therefore, the response (displacement/drift) may be of the same order in a DAD pier and a conventional ductile pier. This is also the case in the foregoing comparison, although the ductile pier discussed here was stiffer and stronger than the DAD pier and hence was expected to undergo less displacement. Despite undergoing similar or even larger displacements, the DAD pier could accommodate the response displacements through rocking mechanism without causing any significant damage to its precast members. On the other hand, although the response displacement was similar or even slightly less in ductile pier, the inelastic response and resulting damage in the form of plastic hinge will necessitate repair and downtime.

\section{DISCUSSION}

This research has investigated the application of DAD to bridge piers. A 40m span prototype bridge was designed using discontinuous longitudinal reinforcement at the columnfoundation interface to allow rocking at a specially detailed armored column-foundation joint. Lateral forces were resisted by gravity load, post-tensioned tendons (simulated during testing) and supplemental energy dissipation devices. A 30\% scaled model was constructed and tested with PD bi-directional lateral forces and axial load. Experimental results confirmed bi-linear elastic behavior with negligible residual displacement. In contrast to the expectation, some energy dissipation was observed even when dissipaters were not being used. This was likely caused by friction within the testing apparatus, particularly at the ball joints. Damage to the pier was minor to a drift of approximately $5.5 \%$. Toppling was assumed to occur when testing was terminated during EQ3 (90\% MCE) due to safety considerations.

Special attention was given to the resistance of large concentrated compressive forces resulting from bi-directional rocking at an extreme corner of the steel-steel interface. Even at high drifts, only minor damage was observed in the form of superficial crushing and hairline cracks. This can be attributed to the diagonal reinforcing bars which transferred the strut forces into the pier and the steel fibers which impeded crack propagation. The energy dissipation devices did not significantly contribute to the pier's performance. Further development of these devices is needed to provide more efficient, reliable energy dissipation on both uplift and re-centering.

Based on the probabilistic nature of the earthquake selection process, it is possible to state the likely outcomes of damage in a performance-based earthquake engineering (PBEE) context. 
For example, as the first earthquake was identified to represent $90^{\text {th }}$ percentile severity at DBE, it can be stated that one can be at least $90 \%$ confident the DAD pier will not be damaged in an earthquake that has a $10 \%$ chance of occurrence in 50 years (DBE). Similarly, as the second earthquake was identified to represent the median $\left(50^{\text {th }}\right.$ percentile) severity at MCE, one can be at least $50 \%$ confident that the DAD pier will sustain only minor and easily repairable damage in an earthquake that has a $2 \%$ chance of occurrence in 50 years (MCE). Nevertheless, it cannot be said that the pier does not collapse in this level of earthquake (i.e. MCE) with some $90 \%$ confidence because the pier did not survive the final earthquake which was identified as $90^{\text {th }}$ percentile severity at MCE. However, it should be noted that this could easily be mitigated by adopting a larger column in the original design and providing a higher overturning resistance. The benefits of such an approach are given in a companion study (Mander et al. 2007) where the seismic vulnerability of bridge piers designed according to New Zealand, Japanese and American specifications is examined.

There are several obvious benefits of DAD apparent from this study: (i) a lack of damage can potentially lead to lower operating and repair costs; (ii) negligible residual displacement will ensure serviceability following a seismic event; (c) precast construction can be utilized to increase reliability and reduce initial (construction) costs. Related studies into these advantages and their expected financial benefits have been investigated by Solberg (2007) and Solberg et al. (2006).

\section{CONCLUSIONS}

Based on this experimental investigation, the following conclusions can be drawn:

1. It can be stated that owners can have high confidence that DAD piers will not sustain damage from a DBE. For an MCE, the pier may undergo minor damage and there should be at least $50 \%$ confidence the DAD pier will not collapse. On the other hand, one can be about $90 \%$ and $50 \%$ confident that the damage in a conventional ductile pier with similar strength will be moderate (repairable) in a DBE and an MCE, respectively. In contrast, the response of neither pier was convincing enough to give high confidence (in the order of $90 \%$ ) of collapse prevention in an MCE. However, the damage in the DAD pier was significantly less than its ductile counterpart in any stage of the test sequence; indicating that damage in bridge piers can be minimized by following DAD principles.

2. Concentrated axial load was resisted by a combination of reinforcing steel and high strength fiber-reinforced concrete. Only minor damage was observed under bidirectional loading up to $5.5 \%$ drift in the pier.

3. The energy dissipation devices utilized in this study provided some additional lateral resistance. These or similar devices are recommended, though more efficient designs may increase their contribution to lateral resistance and dissipation of earthquake energy.

4. No stiffness degradation or residual displacement was observed. This was shown to be due to the rocking mechanism which resulted in bi-linear elastic hysteretic behavior of the pier. Thus, such piers can be used for immediate post-earthquake operational purposes. 


\section{REFERENCES}

Aslam, M., Goddon, W. G., and Scalise, D. T. (1980). "Earthquake rocking response of rigid blocks." Journal of Structural Engineering, 106(2), 377-392.

Dhakal, R. P., Mander, J. B., and Mashiko, N. (2006). "Identification of critical ground motions for seismic performance assessment of structures." Earthquake Engineering and Structural Dynamics, 35(8), 989-1008.

Housner, G. W. (1963). "The behavior of inverted pendulum structure during earthquake." Bulletin of the Seismological Society of America, 53(2), 403-417.

Mander, J. B. (2000). "Damage avoidance seismic design of bridge piers." New Zealand Concrete Society Conference, Wairakei, NZ, NZCS Technical Report TR 23, pp 42- 49.

Mander, J. B. (2004). "Beyond ductility: the quest goes on." Bulletin of the New Zealand Society of Earthquake Engineering, 37(1), 35-44.

Mander, J. B., Basoz, N. (1999). "Seismic fragility curve theory for highway bridges in transportation lifeline loss estimation." Optimizing Post-Earthquake Lifeline System Reliability, TCLEE Monograph No. 16, American Society of Civil Engineers: Reston, VA, 31-40.

Mander, J. B., and Cheng, C. T. (1997). "Seismic resistance of bridge piers based on damage avoidance design." Technical Report NCEER-97-0014 (National Center for Earthquake Engineering Research), State University of New York, Buffalo, NY.

Mander, J. B., Dhakal, R. P., Mashiko, N., and Solberg, K. (2007). "Incremental dynamic analysis applied to seismic risk assessment of bridges." Engineering Structures, DOI:10.1016/j.engstruct.2006.12.015 (Available Online).

Meek, J. W. (1978.) "Dynamic response of tipping core buildings." Earthquake Engineering \& Structural Dynamics, 6(5), 437-454.

Palermo, A., Pampanin, S., and Calvi, G. M., (2005). "Concept and development of hybrid solutions for seismic resistant bridge systems." Journal of Earthquake Engineering, 9(6), 899-921.

Priestley, M. J. N., Sritharan, S., Conley, J. R., and Pampanin, S. (1999). "Preliminary results and conclusions from the PRESSS five-story precast concrete test building." PCI Journal, 44(6), 42-67.

Shing, P. B., Nakashima, M., and Bursi, O. S. (1996). "Application of dynamic test method to structural research." Earthquake Spectra, 12(1), 29-54.

Skinner, R. I., Robinson, W. H., and McVerry, G. H. (1993). An Introduction to Seismic Isolation. John Wiley \& Sons, New York, NY.

Solberg, K. M. (2007). "Financial and experimental investigations into the viability of damage avoidance design." Master of Engineering Thesis, University of Canterbury, Christchurch, New Zealand.

Solberg, K. M., Mander, J. B., and Dhakal, R. P. (2006). "Financial seismic risk assessment of RC bridge piers using a distribution free approach." Proc., 2006 New Zealand Society of Earthquake Engineering (NZSEE) Conference, Napier, New Zealand, paper 20.

Standards New Zealand (1995). Concrete Structures Standard: NZS3101:95. Standards New Zealand, Wellington, New Zealand.

Vamvatsikos, D., and Cornell, C. A. (2004). "Applied incremental dynamic analysis." Earthquake Spectra, 38(2), 523-553. 


\section{LIST OF FIGURE CAPTIONS}

Figure 1: The DAD prototype and specimen: (a) prototype details; (b) specimen details; (c) prototype pushover curve; (d) energy dissipater detail; (e) photo of shoe block reinforcement; and (f) shoe block details.

Figure 2: Test setup: (a) EW elevation view; (b) plan view; (c) photo of the test setup; and (d) schematic of acquisition hardware and the PD experimental procedure.

Figure 3: Quasi-static test: (a) plan view of bi-directional loads; (b) EW and (d) NS forcedisplacement curves; (c) photo of specimen in DARTEC ${ }^{\mathrm{TM}}$ test machine; (e) plan view of drift orbit; and (f) NS and (g) EW displacement profile.

Figure 4: Test results of the DAD pier with energy dissipaters, subjected to EQ1, EQ2, and EQ3: (a) the DAD shoe block at the end of EQ1; force-displacement curves for (b) EW and the analytical prediction pushover curve, (c) EW with and without energy dissipaters, and (d) NS direction; (e) plan view of drift; (f) NS and (h) EW displacement-time plots; (g) rocking at 3\% drift; and (i) minor localized surface crushing at the shoe block corner at the termination of testing.

Figure 5: Test results of the ductile pier, subjected to EQ1, EQ2, and EQ3: (a) photo of spalling at approximately 60 seconds; force-displacement curves for (b) EW and (d) NS direction; (c) photo of bar buckling at approximately 70 seconds; (e) plan view of drift; (f) NS and (g) EW displacementtime plots. 
Table 1: Dimensions and materials of the prototype bridge pier and specimen.

\begin{tabular}{|c|c|c|c|c|}
\hline Parameter & Symbol & Unit & DAD Pier & Ductile Pier \\
\hline \multicolumn{5}{|l|}{ Prototype } \\
\hline Diameter & $D$ & $\mathrm{~mm}$ & 1400 & 1700 \\
\hline Effective Diameter & $D^{\prime}$ & $\mathrm{mm}$ & 1240 & 1540 \\
\hline Width of shoe block & B & $\mathrm{mm}$ & 1700 & --- \\
\hline Height of shoe block & $H_{s}$ & $\mathrm{~mm}$ & 1500 & --- \\
\hline Longitudinal reinforcing & & & 20-D32 & 28-D32 \\
\hline Longitudinal reinforcement ratio & $\rho_{+}$ & & $1.04 \%$ & $0.99 \%$ \\
\hline Transverse reinforcement & & & R20@190 & R20@170 \\
\hline \multicolumn{5}{|l|}{ Specimen } \\
\hline Diameter & $D$ & $\mathrm{~mm}$ & 400 & 500 \\
\hline Gravity Load & $P$ & $\mathrm{kN}$ & 630 & 630 \\
\hline Longitudinal reinforcing bars & & & $16-D 10$ & 24-D10 \\
\hline Longitudinal steel volume & $\rho_{\dagger}$ & $\%$ & 1.00 & 0.96 \\
\hline Transverse spiral reinforcement & & & R6@55 & R6@50² \\
\hline Transverse steel volume & $\rho_{s}$ & $\%$ & 0.60 & 0.51 \\
\hline Shoe block steel & & & D16 & --- \\
\hline Shoe block confinement (HS wire rope) & & & $7 \times 16$ & --- \\
\hline Concrete measured strength & $f_{c}^{\prime}$ & $\mathrm{MPa}$ & 70.6 & 41.2 \\
\hline Shoe block concrete strength & $f_{c}^{\prime}$ & $\mathrm{MPa}$ & 61.5 & --- \\
\hline Shoe block tensile strength ${ }^{1}$ & $f_{+}$ & $\mathrm{MPa}$ & 7.0 & --- \\
\hline Longitudinal steel: yield strength & $f_{y}$ & $\mathrm{MPa}$ & 539 & 539 \\
\hline Ultimate strength & $f_{u}$ & $\mathrm{MPa}$ & 677 & 677 \\
\hline Strain hardening & $\varepsilon_{\text {sh }}$ & $\%$ & 1.8 & 1.8 \\
\hline Strain at ultimate strength & $\varepsilon_{\text {su }}$ & $\%$ & 14.6 & 14.6 \\
\hline Transverse Spiral Steel: yield strength & $f_{y}$ & $\mathrm{MPa}$ & 461 & 461 \\
\hline Ultimate strength & $f_{u}$ & $\mathrm{MPa}$ & 633 & 633 \\
\hline Strain hardening & $\varepsilon_{\text {sh }}$ & $\%$ & 1.4 & 1.4 \\
\hline Strain at ultimate strength & $\varepsilon_{\text {su }}$ & $\%$ & 19.6 & 19.6 \\
\hline
\end{tabular}


Table 2: Earthquake records adopted for PD testing.

\begin{tabular}{|c|c|c|c|c|c|c|c|c|c|c|}
\hline ID & Hazard & PGA (g) & Component & Event & Year & Station & $\phi$ & $M$ & $R(\mathrm{~km})$ & $P G A(g)$ \\
\hline \multirow{2}{*}{ EQ1 } & \multirow{2}{*}{$\begin{array}{l}90 \% \\
D B E\end{array}$} & 0.376 & EW & \multirow{2}{*}{$\begin{array}{l}\text { Imperial } \\
\text { Valley }\end{array}$} & \multirow{2}{*}{1979} & \multirow{2}{*}{ Chihuahua } & 282 & \multirow{2}{*}{6.5} & \multirow{2}{*}{28.7} & 0.254 \\
\hline & & 0.400 & NS & & & & 12 & & & 0.270 \\
\hline \multirow{2}{*}{ EQ2 } & $50 \%$ & 0.800 & EW & \multirow{2}{*}{ Loma Prieta } & \multirow{2}{*}{1989} & \multirow{2}{*}{$\begin{array}{l}\text { Anderson } \\
\text { Dam }\end{array}$} & 270 & \multirow{2}{*}{6.9} & \multirow{2}{*}{21.4} & 0.244 \\
\hline & MCE & 0.787 & NS & & & & 360 & & & 0.240 \\
\hline \multirow{2}{*}{ EQ3 } & $90 \%$ & 0.800 & EW & \multirow{2}{*}{$\begin{array}{l}\text { Superstition } \\
\text { Hills }\end{array}$} & \multirow{2}{*}{1987} & \multirow{2}{*}{$\begin{array}{l}\text { Wildlife } \\
\text { Liquefaction }\end{array}$} & 360 & \multirow{2}{*}{6.7} & \multirow{2}{*}{24.4} & 0.207 \\
\hline & MCE & 0.700 & NS & & & & 90 & & & 0.181 \\
\hline
\end{tabular}

Table 3: Damage states index for bridges as defined by Hazus.

\begin{tabular}{|l|l|l|l|l|}
\hline \multicolumn{2}{|l|}{ Damage State } & Failure Mechanism & Repair required & Outage expected \\
\hline DS1 & None & First Yield & None & No \\
\hline DS2 & Minor/Slight & Cracking, Minor spalling & $\begin{array}{l}\text { Inspect, Adjust, } \\
\text { Patch }\end{array}$ & $<3$ days \\
\hline DS3 & Moderate & Spalling, Bar buckling & Repair components & $<3$ weeks \\
\hline DS4 & Major/Extensive & $\begin{array}{l}\text { Degrading of strength, Bar } \\
\text { fracture }\end{array}$ & Rebuild components & $<3$ months \\
\hline DS5 & Complete/Collapse & Collapse & Rebuild structure & $>3$ month \\
\hline
\end{tabular}




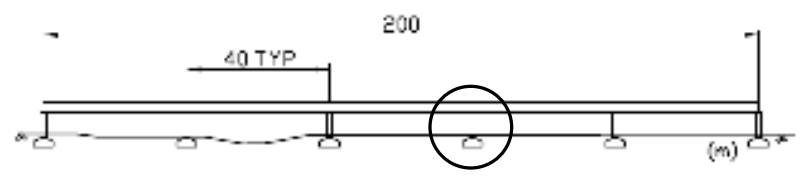

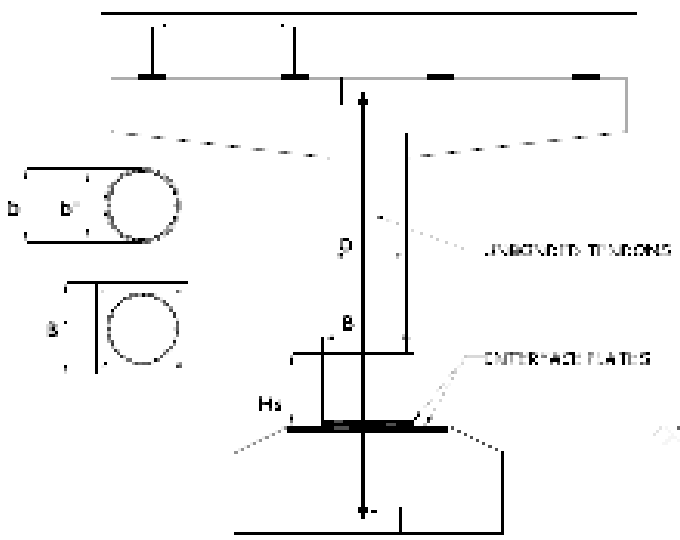

(a)

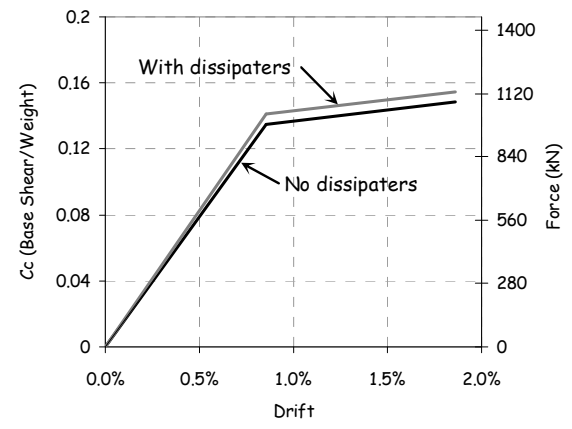

(c)

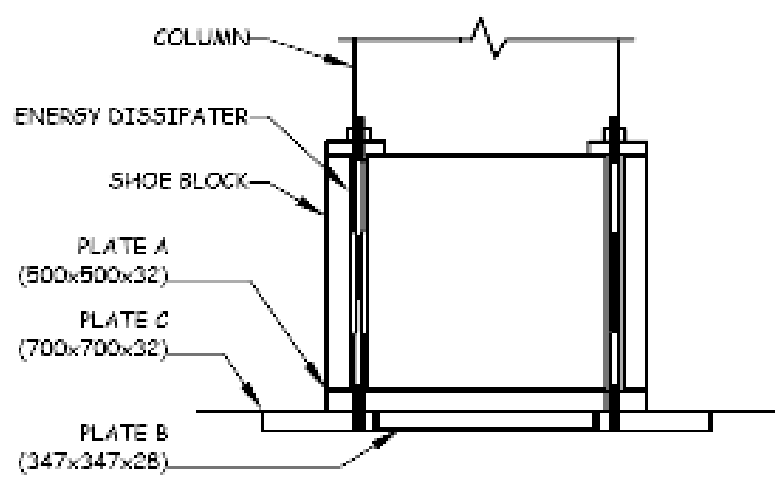

(f)

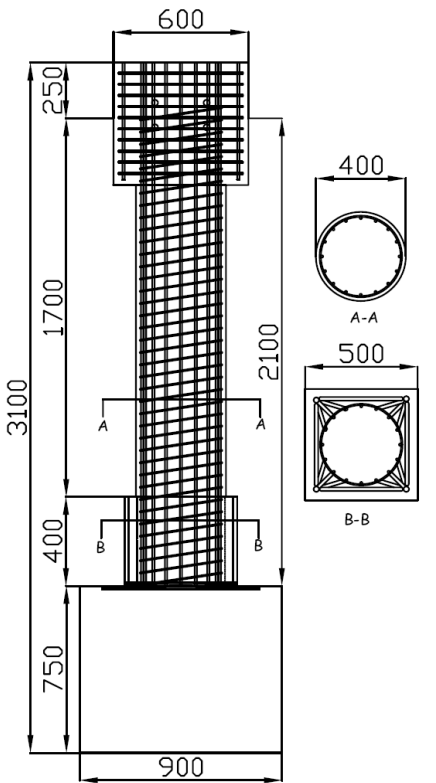

(b)

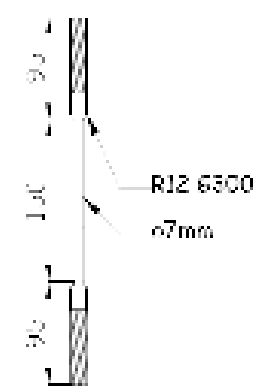

(d)

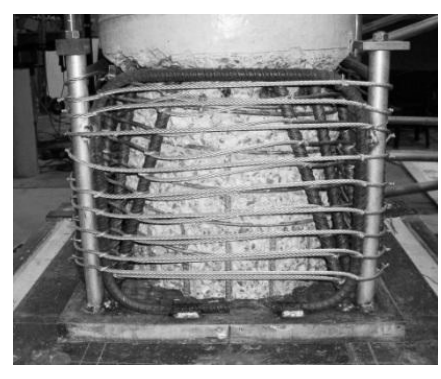

(e)

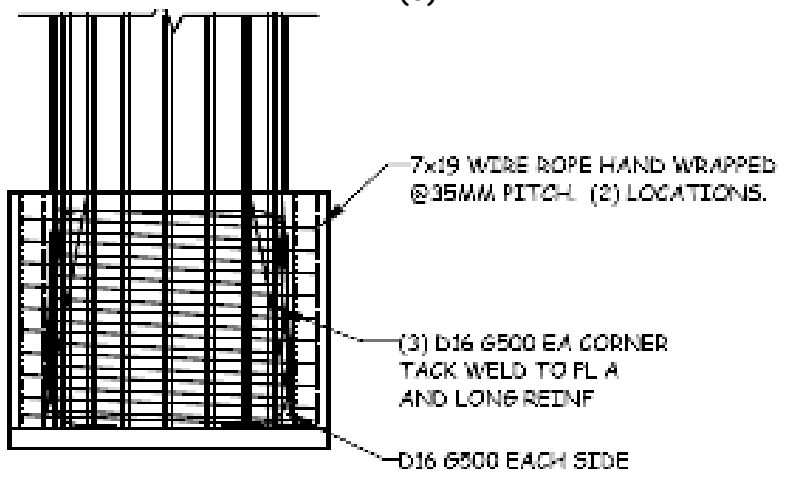

Figure 1: The DAD prototype and specimen: (a) prototype details; (b) specimen details; (c) prototype pushover curve; (d) energy dissipater detail; (e) photo of shoe block reinforcement; and (f) shoe block details. 


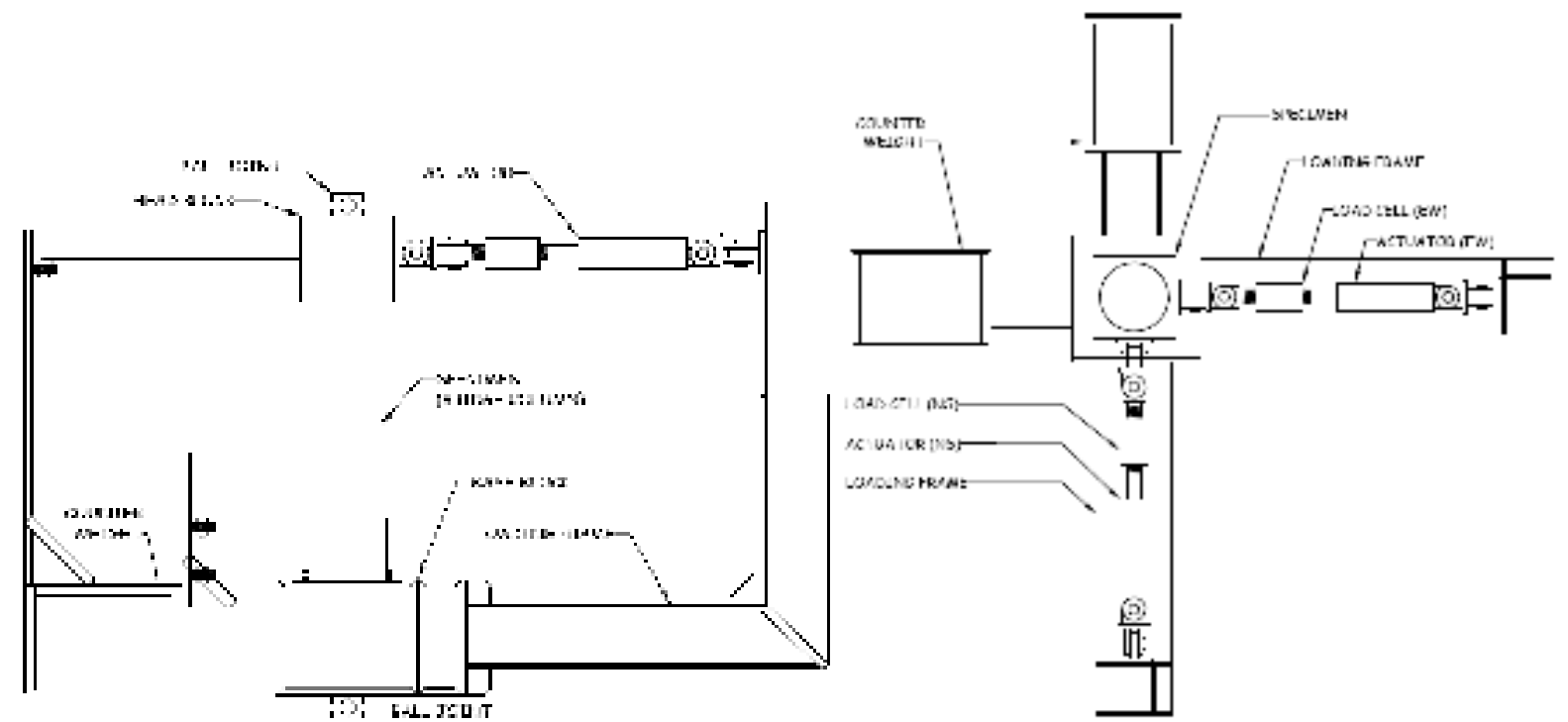

(a)

(b)

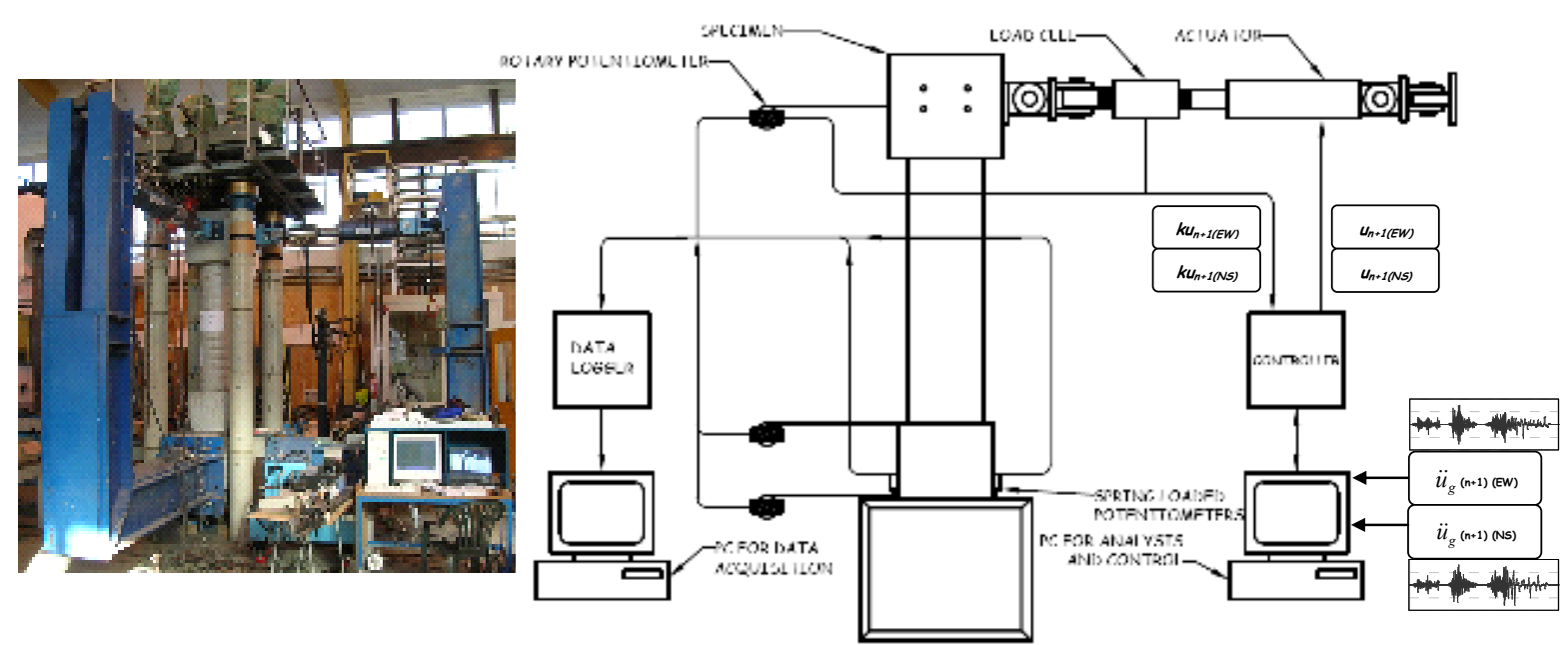

(c)

(d)

Figure 2: Test setup: (a) EW elevation view; (b) plan view; (c) photo of the test setup; and (d) schematic of acquisition hardware and the PD experimental procedure. 

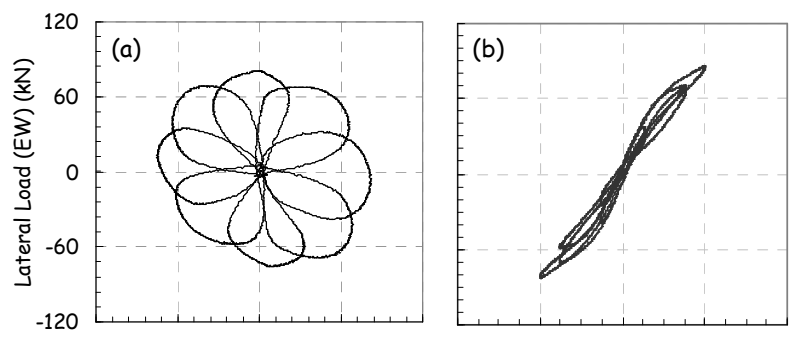

(c)
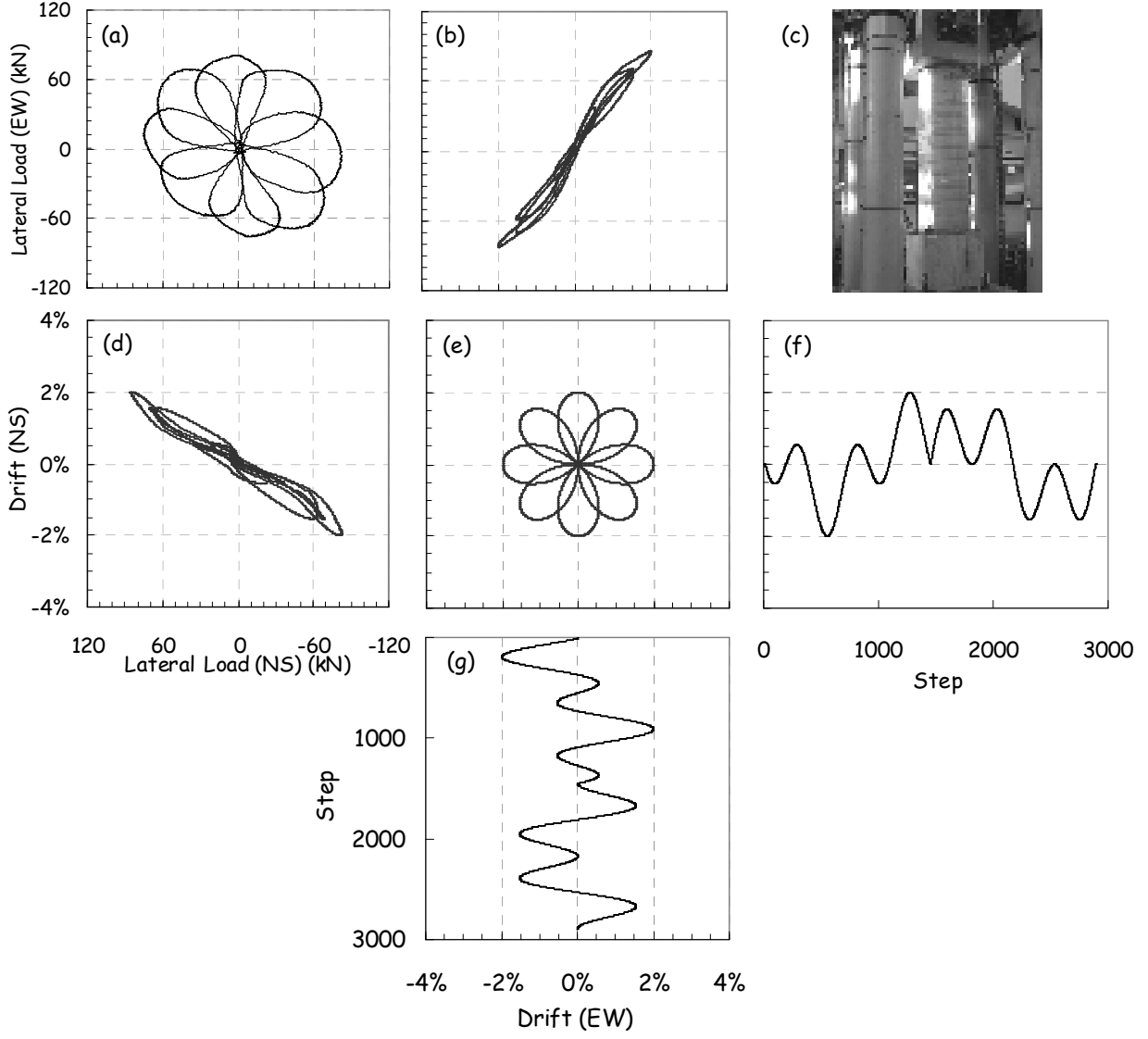

Figure 3: Quasi-static test: (a) plan view of bi-directional loads; (b) EW and (d) NS forcedisplacement curves; (c) photo of specimen in DARTEC ${ }^{\mathrm{TM}}$ test machine; (e) plan view of drift orbit; and (f) NS and (g) EW displacement profile. 


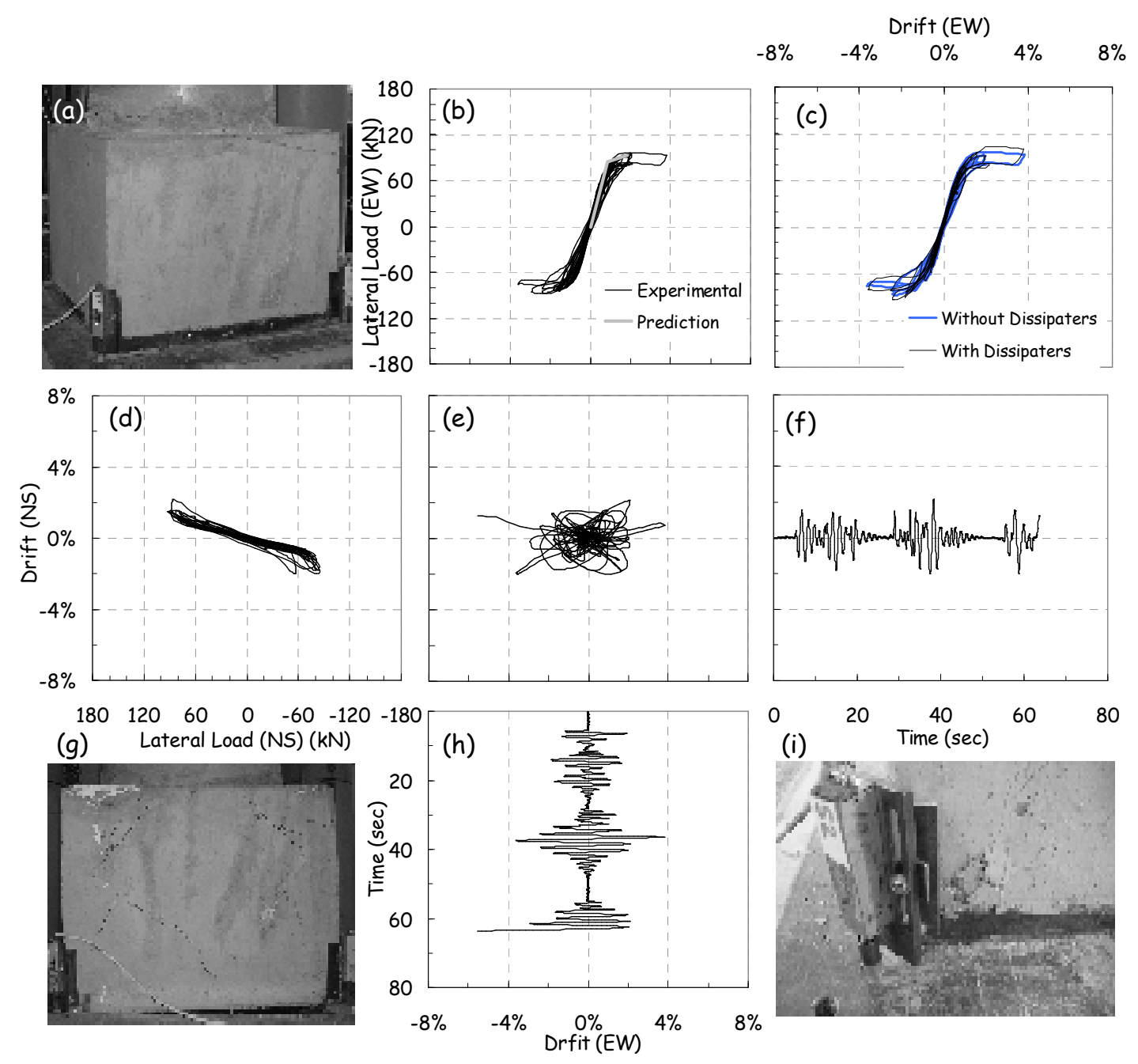

Figure 4: Test results of the DAD pier with energy dissipaters, subjected to EQ1, EQ2, and EQ3: (a) the DAD shoe block at the end of EQ1; force-displacement curves for (b) EW and the analytical prediction pushover curve, (c) EW with and without energy dissipaters, and (d) NS direction; (e) plan view of drift; (f) NS and (h) EW displacement-time plots; (g) rocking at 3\% drift; and (i) minor localized surface crushing at the shoe block corner at the termination of testing. 

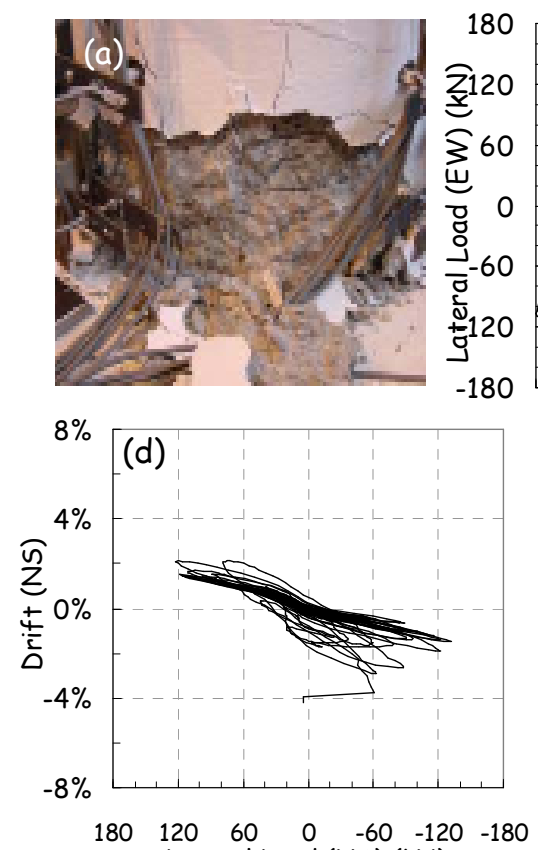

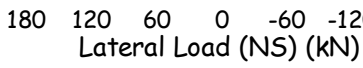
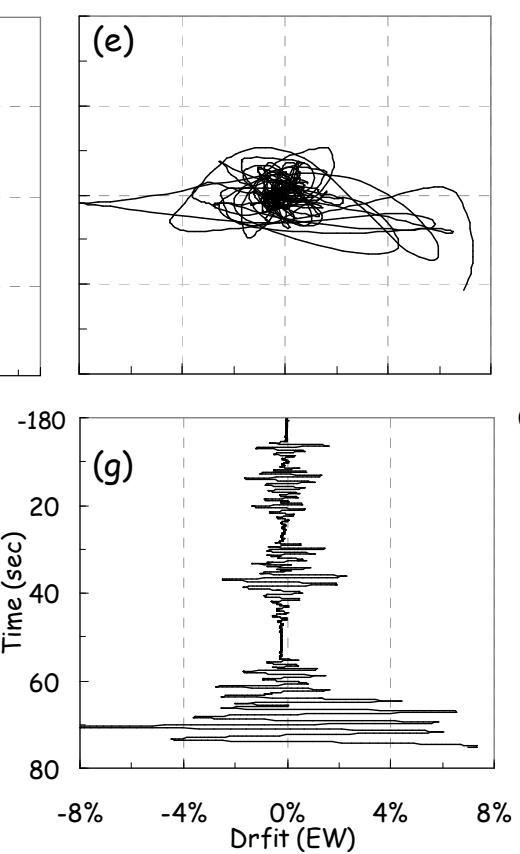

Figure 5: Test results of the ductile pier, subjected to EQ1, EQ2, and EQ3: (a) photo of spalling at approximately 60 seconds; force-displacement curves for (b) EW and (d) NS direction; (c) photo of bar buckling at approximately 70 seconds; (e) plan view of drift; (f) NS and (g) EW displacementtime plots.
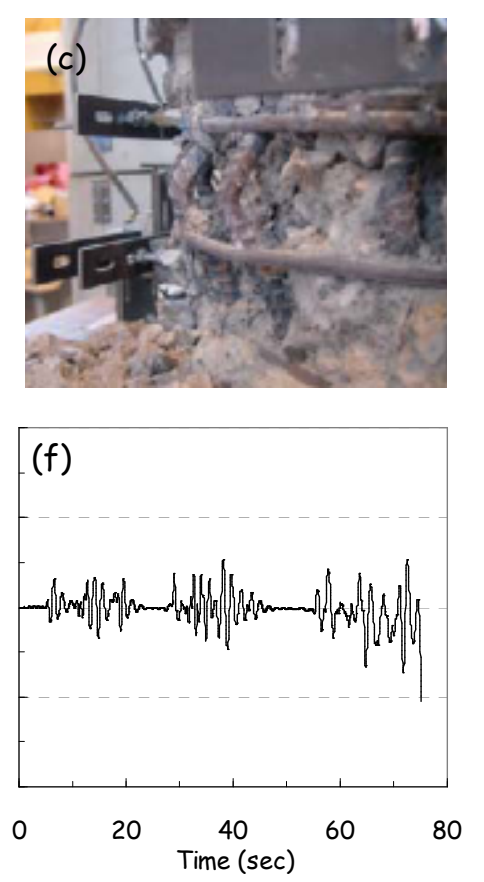